\title{
ENSINO DE CIÊNCIAS BASEADO EM INVESTIGAÇÃO: UMA PROPOSTA DIDÁTICA INOVADORA PARA O USO DE LABORATÓRIOS ON-LINE EM AVEA
}

\section{SCIENCE EDUCATION BASED ON INQUIRY: AN INNOVATIVE DIDACTIC PROPOSAL FOR THE USE OF ONLINE LABORATORIES IN VIRTUAL LEARNING SPACES}

\author{
Aline Coêlho dos Santos ${ }^{1}$ \\ Bruno José de Sousa ${ }^{2}$ \\ Josi Zanette do Canto ${ }^{3}$ \\ Juarez Bento da Silva ${ }^{4}$
}

\begin{abstract}
Resumo: O Ensino de Ciências encontra-se atualmente condicionado a um sistema de ensino ineficaz, com baixo aproveitamento, alto desinteresse dos alunos e pobre em atividades de investigação $e$ experimentação prática. A necessidade por inovação é uma constante. Este estudo apresenta o desenvolvimento de conteúdos digitais, utilizados nas aulas de Ciências, na Educação Básica, por intermédio da construção de um espaço de investigação virtual, com integração de atividades inspiradas no modelo de Aprendizagem Baseada em Investigação (ABInv), Ambiente Virtual de Ensino e Aprendizagem (AVEA) e experimentação prática em Laboratórios Virtuais e Remotos (LVR). Esta pesquisa pauta-se na descrição e discussão do processo de construção do espaço de investigação virtual aqui proposto. Dos resultados obtidos foi possivel identificar dificuldades, como, baixo acervo de laboratórios on-line disponíveis e difícil adequação das atividades e conteúdo ao modelo. Em contrapartida a proposta apresenta-se como uma inovação tecnoeducativa em potencial, podendo ser propulsora de ensino de qualidade, como também despertar no aluno o interesse pela ciência.
\end{abstract}

Palavras-chave: Inovação tecnoeducativa; aprendizagem baseada em investigação; laboratórios virtuais; laboratórios remotos.

\begin{abstract}
The teaching of Science is currently conditioned by an ineffective teaching system, with low achievement, high disinterest from the students and poor in research activities and practical experimentation. The need for innovation is a constant. This study presents the development of digital contents, used in Science classes, in Basic Education, by the construction of a virtual research space, with the integration of activities inspired by the Inquiry-based learning, Virtual Environment for Teaching and Learning and practical experimentation in Virtual and Remote Laboratories (LVR). This research is based on the description and discussion of the process of construction of the virtual research space proposed here. From the results obtained, it was possible to identify difficulties such as low collection of available online laboratories and difficult adaptation of the activities and content to the model. On the other hand, the proposal is presented as a potential techno-educational innovation, being a possible propulsor of quality teaching, as well as awakening in the student the interest in science.
\end{abstract}

Keywords: Techno-educational Innovation; inquiry-based learning; virtual labs; remote Laboratories.

\footnotetext{
${ }^{1}$ Mestranda em Tecnologias da Informação e Comunicação na Universidade Federal de Santa Catarina - UFSC, SC, Brasil. E-mail: aline.cds@live.com.

2 Instituto Federal de Santa Catarina - IFSC, SC, Brasil. E-mail: bruno.sousa@ifsc.edu.br.

${ }^{3}$ Mestranda em Tecnologias da Informação e Comunicação Universidade Federal de Santa Catarina - UFSC, SC, Brasil. E-mail: josizanettedocanto@gmail.com.

${ }^{4}$ Doutor em Engenharia de Gestão do Conhecimento - Universidade Federal de Santa Catarina - UFSC, SC, Brasil. E-mail: juarez.silva@ufsc.br.
} 


\section{INTRODUÇÃO}

Há anos o sistema de ensino no Brasil vem enfrentando críticas negativas e questionamentos confrontantes em relação à sua prática e eficácia na aprendizagem. No entanto, esse quadro tem se agravado, significativamente, nos últimos anos, principalmente no que se refere ao Ensino de Ciências, propulsor de desenvolvimento científico e tecnológico de um país (AULER; DELIZOICOV, 2001; CASTRO, 2004; SILVA, 2006).

Castro (2004), quando focaliza, no Ensino de Ciências, sugere que todo empenho em investigação e experimentação que acarretou no avanço científico dos últimos séculos, não tem feito parte do ambiente escolar. $O$ mesmo ainda reitera que, apesar de haver "currículos e programas bastante atualizados, estes se encontram submetidos a tratamento didático obsoleto, em desacordo com o processo de fazer e pensar ciências".

A necessidade por inovação no sistema de ensino torna-se ainda mais evidente quando frente às atuais gerações e ao advento das Novas Tecnologias da Informação e Comunicação (NTICs). Nesse sentido, o uso de Tecnologias Educacionais aliadas a propostas de ensino e Aprendizagem Baseada em Investigação (ABInv), apresenta-se como uma inovação no processo educacional, pois intervém nos mecanismos tradicionais de ensino, aproximando a teoria da prática, promovendo, dessa forma, a construção do conhecimento por meio de experimentação prática, investigação e discussões.

Nesse sentido, o presente estudo tem o objetivo de apresentar o desenvolvimento de conteúdos digitais, utilizados nas aulas de Ciências, na Educação Básica, por meio da construção de um espaço de investigação virtual, aqui descrito como uma Sequência Didática (SD), do qual integram atividades inspiradas no modelo de Aprendizagem Baseada em Investigação (ABInv), Ambiente Virtual de Ensino e Aprendizagem (AVEA) e experimentação prática em Laboratórios Virtuais e Remotos (LVR).

Esse estudo se configura como um documento norteador que poderá contribuir para o entendimento de professores que desejam inovar, ou seja, pretendem integrar tecnologias educacionais em suas aulas, ao mesmo tempo que se preocupam em promover um ensino completo, desenvolvendo, em seus alunos, a autonomia, o senso de como fazer ciência e construir o conhecimento, e a melhoria em sua qualidade de estudo e motivação em estudar.

\section{REFERENCIAL TEÓRICO}

\subsection{Aprendizagem Baseada em Investigação no Ensino de Ciências}


A ABInv, também conhecida como 'Aprendizagem Baseada em Inquérito', 'Aprendizagem Baseada em Indagação', ou ainda 'Inquiry-Based Learning' (IBL), de acordo com Vieira (2012), é um modelo de ensino e aprendizagem com uma estratégia centrada no estudante, que trabalha de maneira colaborativa na solução de problemas por intermédio do método científico, tendo o professor como um mediador desse processo. Este é responsável por fazer o aluno refletir sobre suas experiências, orientando-o a questioná-las e apresentar soluções, levando-o a uma situação de construção de conhecimento.

Cabe ressaltar que, apesar de sua mensurável atualidade, este modelo de aprendizagem já era tratado pelos Padrões Nacionais para o Ensino de Ciências (NSES - National Science Education Standards) nos Estados Unidos, em 1996, e que estes a definiam como "as diferentes formas pelas quais os cientistas estudam o mundo natural e propõem explicações baseadas em evidências resultantes de seu trabalho pesquisa" (NSES, 1996).

Valente (2008) explica que ABInv é uma perspectiva de pesquisa, ou seja, uma "Investigação Científica" que viabiliza ambientes de aprendizagem necessários e condizentes à realidade presente no contexto escolar. Ele defende que esse ambiente de aprendizagem deve ser provido de bom relacionamento aluno-professor, de experimentação prática para investigação, materiais e recursos tecnológicos, além de espaços para a formação, orientação, troca de ideias entre aluno-aluno e alunoprofessor, discussões e divulgação dos trabalhos desenvolvidos.

Em contribuição, Dyasi (2014) propõe que esse modelo de aprendizagem exige competências necessárias para essa investigação, sendo elas, "desenvolver perguntas, realizar planejamento de pesquisa, utilizar instrumentos de medição, observar, prever, recolher e analisar dados, formular explicações e apresentar as suas conclusões".

Nesse sentido, as práticas de investigação envolvem atividades em que os alunos interagem mais intensamente com materiais de apoio, que podem ser recursos tecnológicos ou não, mas que permitam a experimentação e colaboração com outros estudantes durante sua pesquisa (POON; TAN; TAN, 2009).

De Azevedo (2004) esclarece que, para que uma atividade seja considerada investigativa é preciso que, além do processo de experimentação, o aluno tenha a oportunidade de refletir, discutir e relatar sua experiência, e que essa experiência faça sentido para o aluno.

Para o projeto internacional Go-Lab (Global Online Science Labs for Inquiry Learning at School, em português "Laboratórios Online Globais de Ciências para o Aprendizado de Inquérito na Escola"), a ABInv pode ser construída por meio de um ciclo de inquérito capaz de sintetizar o processo de pesquisa em um ciclo mais adequado, que melhor integre o uso de novas tecnologias na educação, como a diversidade de 
laboratórios online existentes, obedecendo etapas bem definidas, como: orientação, contextualização, investigação, discussão e conclusão.

Como podemos observar, a aprendizagem Baseada em Investigação consiste em uma estratégia de ensino capaz de instigar no aluno o interesse pela ciência, além de motivá-lo a estudar, pois este se perceberá envolvido diretamente com os conteúdos e temas discutidos.

\subsection{AVEA - Moodle - Laboratórios Online}

O chamado AVEA (Ambiente Virtual de Ensino Aprendizagem), ainda está muito associado ao ensino à distância, no entanto, ele vem se tornando uma ferramenta tecnológica e inovadora para ser usado não somente em cursos a distância, mas também em cursos presenciais, oferecendo autonomia e exigindo disciplina dos alunos.

Conforme afirma Moran (2003), ensinar e aprender, hoje, não se limita ao trabalho dentro da sala de aula. Esse processo sugere uma transformação do que fazem dentro e fora dela, no presencial e no virtual, além de um planejamento das ações de pesquisa e de comunicação que possibilitem continuar aprendendo em ambientes virtuais, acessando páginas na Internet, pesquisando textos, recebendo e enviando novas mensagens, problematizando questões em fóruns ou em salas de aula virtuais, divulgando pesquisas e projetos.

Dentro desse contexto, desenvolvido por Dougiamas e Taylor (2002), o Moodle foi concebido com o intuito de servir de ambiente para a aprendizagem colaborativa, uma vez que apresenta uma perspectiva construtivista. Assim, o Moodle foi desenhado para apoiar e promover a integração entre as pessoas interessadas em desenvolver ambientes de aprendizagem construtivista, centrado no aluno.

Antonenko, Toy; Niederhauser. (2004) apresentam uma análise do Moodle enfatizando as particularidades do ambiente para o atendimento de cinco aspectos que caracterizam um ambiente construtivista, são eles: psicológicos, pedagógicos, tecnológicos, culturais e pragmáticos. Os autores destacam "a aprendizagem situada integra quatro fatores críticos que maximizam a aprendizagem dos alunos em potencial: conteúdo, contexto, comunidade e participação".

É percebido que os AVEA têm sofrido aprimoramentos, e também se enriquecido com a integração de novos recursos tecnológicos, como os laboratórios online, que, nos últimos anos, têm se consolidado nos diferentes espaços de ensino.

Laboratórios Online consistem em laboratórios virtuais e remotos, ferramentas tecnológicas que permitem atividades de experimentação, seja ela por meio de simulação, ou manipulação real do experimento, viabilizadas por dispositivos conectados à internet (SILVA, 2006). 
De acordo com Silva (2006), laboratórios virtuais, ou melhor, "laboratórios baseados em simulação", reproduzem o funcionamento dos aparatos que se encontra em um laboratório, possibilitando que o aluno aprenda sobre seu funcionamento. Já, laboratório remoto, o aluno é capaz de "manejar os aparatos que se encontram no laboratório físico" a partir de qualquer lugar.

\section{METODOLOGIA}

Esta pesquisa caracteriza-se como qualitativa de cunho exploratório descritivo, pois, segundo Gil (1991), expõe diferentes interpretações que partem da visão de mundo do indivíduo, proporcionando uma análise criteriosa que focaliza no objeto de estudo por meio de análise de dados indutiva e levantamento de dados a seu respeito.

Nesse sentido, este artigo está pautado na descrição e discussão do processo de construção do espaço de investigação virtual aqui proposto, ou seja, nas sequências didáticas desenvolvidas para melhor integração do uso de laboratórios virtuais e remotos nas aulas de biologia, no Ensino Médio.

A construção das sequências didáticas será pautada na sistematização de passos definidos pelo projeto de pesquisa Go-Lab, são eles: Orientação; contextualização; investigação, discussão e conclusão.

\section{RESULTADOS}

A sequência didática mostrada, a seguir, foi construída como parte do trabalho desenvolvido pelo grupo de pesquisa Rexlab/UFSC - Campus Araranguá, para o projeto gt-mre (Grupo de Trabalho em Experimentação Remota Móvel), que tem como objetivo "desenvolver e implantar uma plataforma que integre AVEA por meio da disponibilização de conteúdos didáticos abertos online, acessados por dispositivos móveis ou convencionais, e complementados pela interação com experimentos remotos". (GTMRE, 2017).

Essa sequência didática pode ser acessada pelo site do projeto (http://gtmre.ufsc.br/moodle/), no ícone cursos juntamente com outras sequências que expõem, de forma clara e prática, o uso da investigação no processo de ensino, ou seja, adéqua o conteúdo a ser ministrado em sala de aula nos direcionamentos propostos pelo modelo ABInv, incorpora-os em AVEA e possibilita acesso à experimentação remota.

A construção desta priorizou três fortes pontos, característicos do modelo de ensino aqui explorado, são eles: o enquadramento do aluno como protagonista e principal responsável por sua aprendizagem; a estruturação da aula frente a uma indagação central; e, por fim, a possibilidade de realizar atividades de investigação por meio de experimentação prática. 
Para um melhor entendimento sobre a construção da Sequência Didática em discussão, o seu desenvolvimento obedeceu às seguintes etapas: busca bibliográfica sobre ABInv; busca por laboratórios online livres adequados para a disciplina de ciências; escolha dos laboratórios online para SD; definição do tema, elaboração da indagação central e definição do público-alvo; construção do plano de aula; exploração de ferramentas no moodle; elaboração de material didático; desenvolvimento de SD no moodle; e, por fim, aplicação prática de SD para o público-alvo escolhido.

A estratégia de construção da SD foi definida pelo grupo de pesquisa Rexlab, após muitas discussões e estudos, e consolidação de parceria com o Projeto Go-Lab, utilizando as etapas propostas: orientação; contextualização; investigação, discussão e conclusão.

Após muitas buscas por laboratórios remotos e virtuais disponíveis na web, percebeu-se a escassez desses recursos para a disciplina de ciências e biologia, principalmente no que se refere aos laboratórios remotos. No entanto, o microscópio remoto, disponibilizado pelo grupo de pesquisa Rexlab, no site http://relle.ufsc.br/, coube perfeitamente à proposta, e, portanto foi escolhido para ser explorado nessa SD.

Em sequência, foi realizado um estudo sobre a base curricular de ciências para cada ano das séries finais do Ensino Fundamental, da Educação Básica. Então definiuse como tema central "O mundo das Plantas", para o seguinte público-alvo: sextos e sétimos anos.

Dentro do tema central, foi, então, elaborada uma indagação central, com o intuito de motivar os alunos para a busca do conhecimento, por meio de investigação: "Você sabia que algumas espécies de plantas mudam a coloração das suas folhas durante estações frias e/ou perdem essas folhas?". A seguir foi construído o Plano de Aula, e, logo, a construção da SD no Moodle.

\subsection{Construção e apresentação da SD}

Como podemos visualizar na Figura 1, essa SD está dividida em 5 etapas: orientação, contextualização, experimentação, discussão e conclusão.

A primeira etapa do ciclo, denominada orientação, é o espaço onde o aluno tem contato com a problematização e os questionamentos acerca do tema que se pretende discutir (GO-LAB, 2016). Procurou-se, nessa perspectiva, deixar claros os objetivos para a realização das atividades propostas, disponibilizar um questionário de conhecimento prévio, bem como colocar o aluno diante de uma problemática real, com alguns outros questionamentos já definidos. E que, a partir destes, ele mesmo fosse capaz de elaborar novas indagações. 
Sendo assim, foi elaborada, para a conclusão dessa primeira etapa: Objetivos (I); Questionário Inicial de conhecimentos prévios (II); Situação Problema (III); Indagações (IV).

Na segunda etapa, contextualização (Figura 2), é o momento em que o aluno entra em contato com uma série de informações sobre os problemas a serem resolvidos, e, nessa fase, o discente constrói hipóteses sobre os problemas que pretende investigar e responder.

Como forma de contribuir para o trabalho autônomo do aluno, o professor pode proporcionar-Ihe ferramentas, como, software de pesquisa, atividades de construção de mapas conceituais, atividades que permitam que o aluno relacione os conceitos explorados com suas respectivas definições, entre outras (GO-LAB, 2016).

Nesse sentido, a contextualização contou com:

I. Breve abordagem conceitual do assunto, com ilustrações explicativas, animais e vídeos, ou seja, o mais didático e atrativo possível.

II. Atividade de contextualização, reforçando os conceitos investigados em leitura e pesquisa. 
Figura 1. Imagem parcial da $1^{a}$ etapa da SD - Orientação

Contextualização

Investigação

Discussão

Conclusão
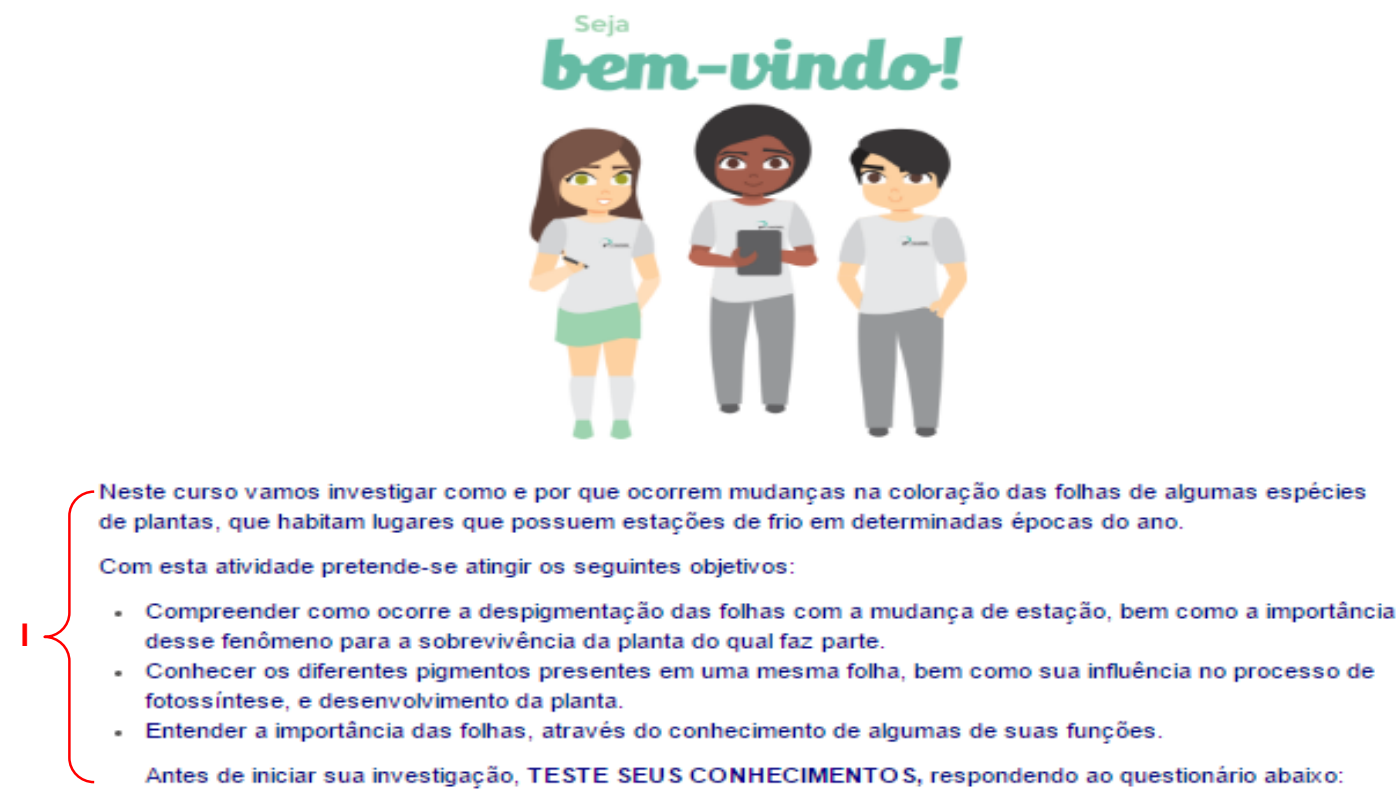

Questionário Inicial

II

Imagens como estas são comuns de serem percebidas no outono e invemo, em locais de clima temperado, ou seja, que possuem as quatro estações do ano bem definidas.

É possivel então perceber, que essas situações são características comuns presentes em plantas que habitam lugares com estações de frio e pouca luminosidade, representado ser uma adaptação evolutiva favorável, que permite a sobrevivência e reprodução das mesmas.

- Mas que tipo de fenômeno ocorre na natureza para que folhas verdes mudem sua coloração?

- Será que elas mudam de cor, ou perdem a cor?

- E por que será que são verdes?

- Aliás pra quê folhas em uma Planta??

Não fique na dúvida! Entenda porque isso ocorre na natureza:
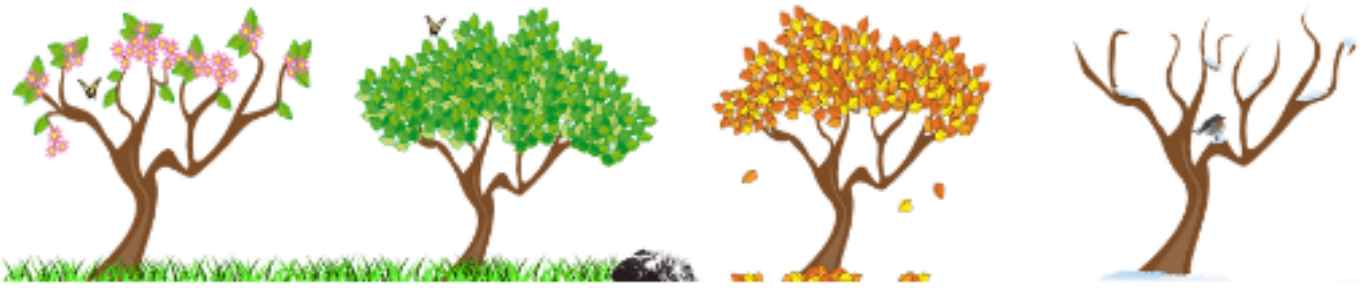

Fonte: https://pixabay.com

Imagem: Mudança de coloração e perda das folhas decorrentes da chegada do outono e invemo.

Fonte: Gt-mre, 2017. 
Figura 2. Etapa Contextualização

Orientação Contextualização Investigação Discussão Conclusão

Primeiro é preciso entender:

1. Por que algumas folhas são verdes, outras avermelhadas, amarelas ou arroxeadas?

2. O que dá cor as folhas das plantas?

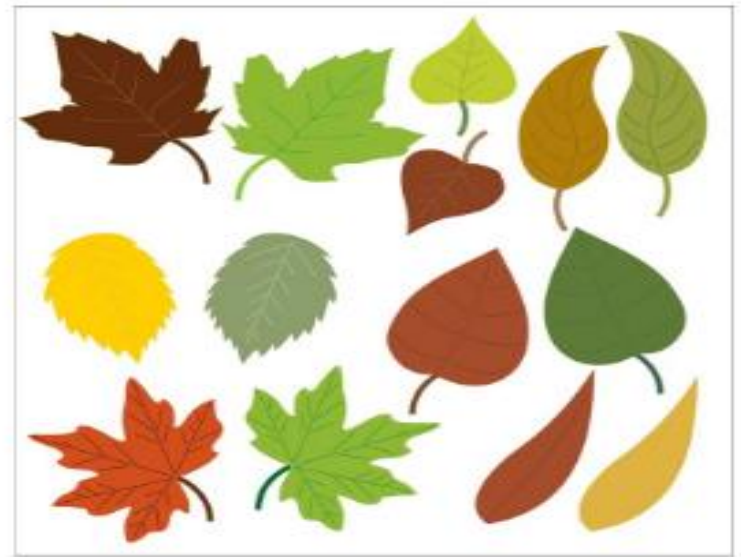

PIGMENTAÇÄO DAS FOLHAS OU PIGMENTOS FOTOSSINTETIZANTES
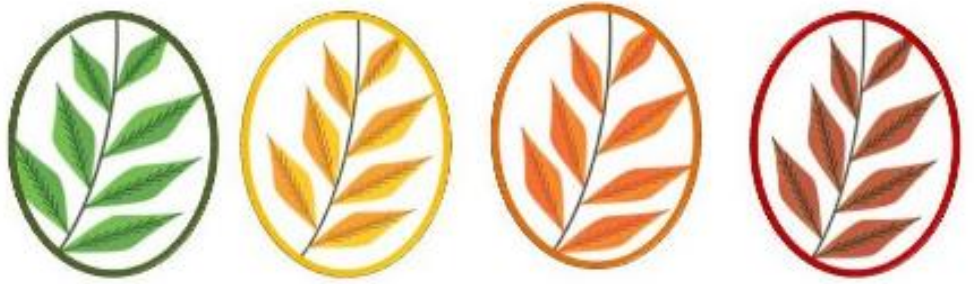

As plantas, seres fotossintetizantes, possuem dentro de suas células, organelas chamadas de cromoplastos que contém pigmentos, necessários à realização fotossíntese, e que dão cor as suas folhas.

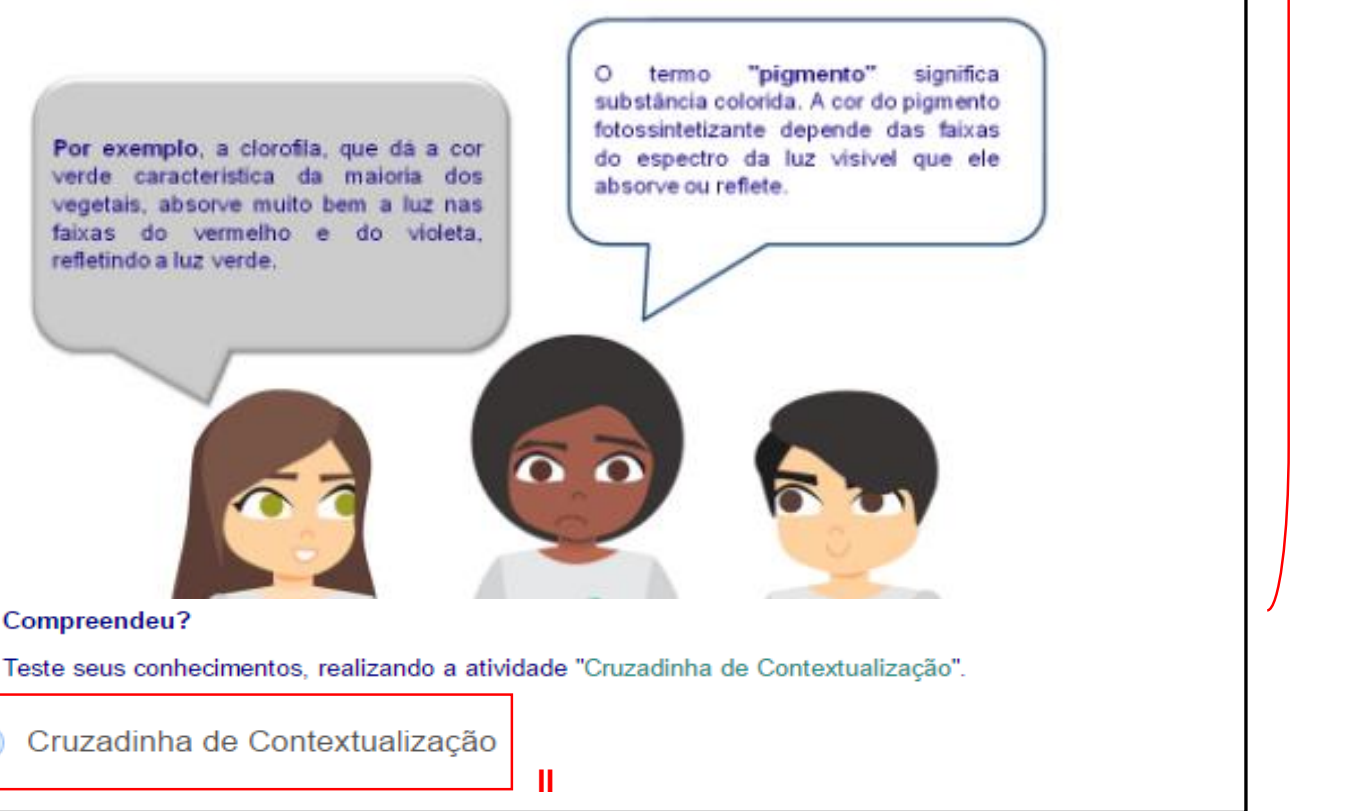

Fonte: Gt-mre, 2017. 
Na Investigação (Figura 3), etapa crucial dessa SD, é o momento em que o aluno pode pôr em prática, aquilo que, até então, estava sendo visto em teoria, ou seja, é a interação real com experimentação prática remota, que envolve observação, exploração, experimentação e interpretação de dados (GO-LAB, 2016).

Figura 3. Etapa Investigativa

Orientação Contextualização Investigação Discussão Conclusão

Utilizando a Experimentação Remota "Microscópio" no link, você poderá colocar em prática seus conhecimentos sobre Pigmentação Foliar e entender como ocorre o processo de despigmentação durante estações frias.

\section{Link para Experimento Remoto Microscópio}

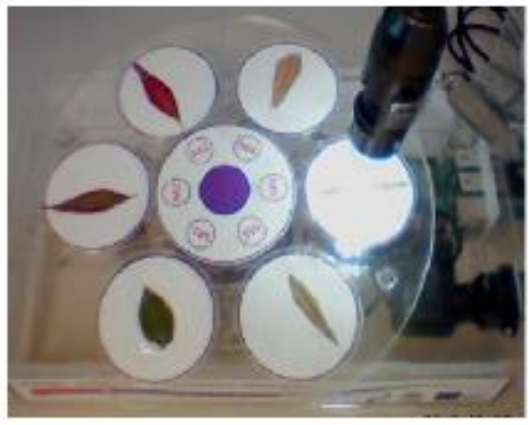

\section{Relatório sobre o experimento II}

\section{Relatório sobre o experimento}

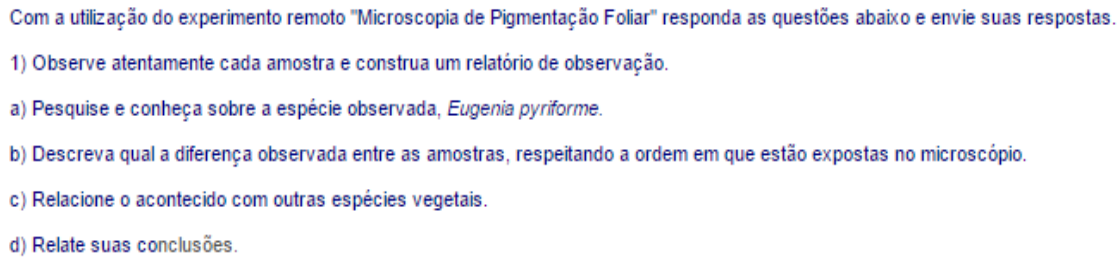

Fonte: Gt-mre, 2017.

Como forma de atender a essa etapa, é necessário:

I. A disponibilização de laboratório online (Remoto ou Virtual) para experimentação prática; 
II. Desenvolvimento de atividade prática, como por exemplo, elaboração de Relatório de Experimentação Prática.

As duas últimas etapas são marcadas pela intensa colaboração e discussão de resultados, como de conclusões e surgimentos de novos problemas. A discussão consiste na etapa de compartilhar um processo de investigação e seus resultados, e, nesse momento, a comunicação pode ser vista como um processo em que os alunos apresentam e comunicam suas descobertas e conclusões de pesquisa, ou seja, enquanto ouvem os outros acabam articulando seus próprios entendimentos (GO-LAB, 2016).

Já, a conclusão é uma etapa para indicar as conclusões básicas de um estudo, ou seja, nessa fase, os alunos abordam suas perguntas ou hipóteses originais de pesquisa e consideram se estas estão respondidas ou apoiadas pelos resultados da investigação (GO-LAB, 2016).

Sendo assim, para os espaços de discussão e conclusão, foram elaboradas atividades colaborativas de pesquisa e reflexão, que os alunos necessitassem dos conhecimentos adquiridos até então, principalmente na fase investigativa, e que pudessem relacionar a outros fenômenos que ocorrem no mundo natural. Feito isso, que pudessem compartilhar os resultados com os colegas, e discutir sobre esses.

Podemos observar, na figura 4 e 5 , representando parte da discussão e conclusão, atividade que podem fazer parte dessas etapas.

A Figura 4 retrata a atividade proposta na fase de discussão, logo após a experimentação e construção de relatório de atividade prática. É interessante observar que se trata de um fórum de discussão, ou seja, permite que todos os colegas tenham acesso à atividade realizada, e, ainda, possam contribuir, realizando críticas e questionamentos a respeito.

Figura 4. Atividade proposta na discussão

\section{Fórum para discussão}

Juntamente com seus colegas, procure espécies vegetais que durante 0 outono e inverno sofrem com essas mesmas mudanças investigadas até então, ou seja, que tem perda de pigmentos fotossintetizantes durante as estações frias. Feito isso, busque por fotos

dessas mesmas espécies. Utilize o fórum de discussão para compartilhar a atividade realizada.

ACRESCENTAR UM NOVO TÓPICO DE DISCUSSÃO

Fonte: Gt-mre, 2017.

As atividades planejadas para a conclusão (Figura 5) tiveram cunho avaliativo, e foram representadas por dois tipos: a primeira, caracterizada como colaborativa, propõe a construção de um vídeo realizando experimento prático do tema em questão; e a segunda remete ao questionário inicial, respondido na etapa da orientação apenas com 
conhecimentos prévios, e, agora, nessa etapa, com conhecimentos mais aprofundados a respeito do tema.

Figura 5. Atividades proposta na discussão

Relate essa experiência, assim como seus resultados em um vídeo, e compartilhe com seus colegas!

\section{Atividade Final - Criando seu vídeo}

\section{Relate suas experiências}

Para verificar se suas concepções sobre o assunto foram modificadas e concluir o curso, responda o questionário abaixo.

\section{Questionário Final}

Fonte: Gt-mre, 2017.

Em resumo, podemos destacar algumas ações que foram relevantes para a consolidação de cada etapa, como mostra a Figura 6, logo abaixo.

\section{Figura 6: Etapas da SD e seu desenvolvimento}

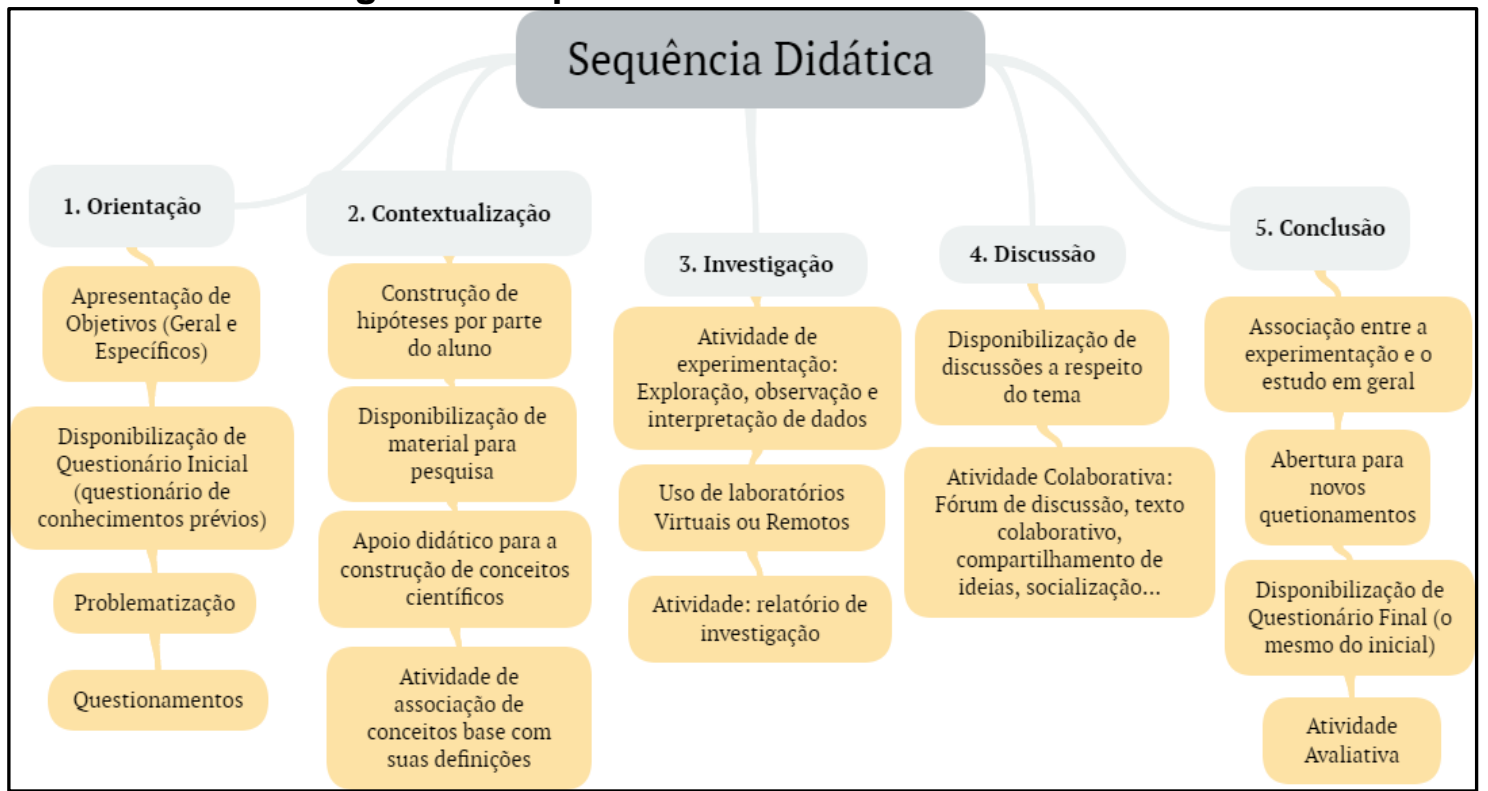

Fonte: Autores.

\section{CONSIDERAÇÕES FINAIS}

De acordo com os dados apresentados, é possível esclarecer pontos fortes a respeito do modelo de ensino ABInv. Primeiramente, que ele não se opõe ao método tradicional, e que não se caracteriza como um modelo de ensino único e engessador do processo de ensino-aprendizagem, mas que é uma possibilidade de tornar o aluno principal responsável pelo seu aprendizado e, ainda, motivá-lo para o interesse na carreira científica, desenvolvendo, desde cedo, o pensar e fazer ciência. 
É possível identificar algumas dificuldades encontradas na construção da sequência didática, como o desenvolvimento de atividades que não tenham respostas prontas e diretas na web, mas que necessitem de uma busca em diferentes fontes por parte do aluno, e a construção de uma resposta autoral. Outro ponto bastante pertinente, é que ainda são poucos os laboratórios remotos existentes e disponíveis livremente para as disciplinas de ciências e biologia. Já os laboratórios virtuais, apesar de possuírem um acervo e disponibilidade maior, também apresentam carência na sua oferta, se considerarmos o potencial para desenvolvimento dos mesmos.

Devido à problemática supracitada entende-se que um dos principais desafios para a construção da SD é a definição do tema, já que as atividades ligadas à experimentação são as que definem esse caráter investigativo que a mesma possui e que necessariamente precisam da disponibilização de laboratórios online. Outro fator notável é que o tema central aborde problemáticas reais e gere discussões, sendo nesse caso, de suma importância que a indagação inicial desperte interesse nos alunos, pois assim eles estarão instigados a resolver o problema e se empenharão na investigação.

Apesar de mais utilizada em cursos de nível superior ou técnico, a presença da ABInv na Educação Básica pode ser possível, basta o professor selecionar o conteúdo, do qual deseja utilizar a ABInv, e adequar as atividades propostas, para o cumprimento dos objetivos inerentes ao método.

Para que ocorra essa adequação ao método, os seguimentos expostos nessa pesquisa podem servir como direcionadores, mas não impedem que o professor adapteos conforme a sua realidade contextual.

É possível, também, concluir que o modelo ABInv é facilmente enquadrado em diferentes modalidades, apresentando-se bastante funcional à distância, como ocorrendo perfeitamente bem, com apenas a condução do professor na dinâmica de sala aula. Isso ocorre se o professor fizer um bom planejamento, deixar bem claro ao aluno de que maneira eles vão 'aprender', e ainda, que defina bem os objetivos de aprendizagem que se pretende atingir com aplicação da SD.

Por fim, a SD aqui retrata, apesar de estar disponibilizada virtualmente, com algumas adaptações, pode ser enquadrada como uma sequência didática, com aplicação presencial ou à distância, conforme realidade contextual existente (necessidade do professor, recursos disponíveis, interesses dos alunos, entre outros).

No entanto, vale ressaltar que os conteúdos disponibilizados na Web, além de trazerem esse aspecto visualmente mais atrativo, podem ser acessados a todo instante, de qualquer lugar, por meio de dispositivos móveis (smartphones, tablets e computadores, por exemplo) e permitir, ainda, que o aluno realize as atividades no seu tempo, oportunizando a ele poder voltar às etapas quantas vezes achar necessário, ou seja, personaliza o ensino para cada ritmo de aprendizagem. 


\section{REFERÊNCIAS}

ANTONENKO, P.; TOY, S.; NIEDERHAUSER, D. Modular Object-Oriented Dynamic Learning Environment: What Open Source Has To Offer. In: Association for

Educational Communications and Technology, 27th, Chicago, IL, October 19-23, 2004. Disponível em:

<http://www.eric.ed.gov/ERICWebPortal/contentdelivery/servlet/ERICServlet?accno=E D485088>. Acesso em: 28 abr. 2017.

AULER, Décio; DELIZOICOV, Demétrio. Alfabetização científico-tecnológica para quê?. Ensaio Pesquisa em Educação em Ciências, v. 3, n. 2, p. 122-134, 2001.

AZEVEDO, Maria Cristina P. Stella. Ensino por investigação: problematizando as atividades em sala de aula. In: CARVALHO, A. Ensino de Ciências:unindo a pesquisa e a prática, 2004, p. 19-33.

CASTRO, A. D. Prefácio. In: CARVALHO, A. M. P. (Org). Ensino de Ciências: unindo a pesquisa e a prática. São Paulo: Pioneira Thomson Learning, 2004. p. 3- 21.

DOUGIAMAS, M; TAYLOR, P. C. Interpretive analysis of an internet-based course constructed using a new courseware tool called Moodle. 2002. Disponível em:<http://dougiamas.com/writing/herdsa2002/> Acesso em: 27 mar. 2017.

DYASI, Hubert. Enseñanza de la ciencia basada en la indagación: razones por las que debe ser la piedra angular de la enseñanza y el aprendizaje de la ciencia. Innovec -

La Enseñanza de La Ciencia En La Educación Básica: Antología sobre Indagación, México, p.7-16, 2014. Disponível em: <http://innovec.org.mx/home/>. Acesso em: 4 maio 2016.

GIL, Antonio Carlos. Como elaborar projetos de pesquisa, São Paulo: Atlas, 1991.

GO_LAB. Project - Global Online Science Labs for Inquiry Learning at School. 2016. Disponível em: <http://go-labproject.eu/tips-tricks>. Acesso em: 9 fev. 2017.

GT-MRE. Sobre o Projeto. Disponível em: <http://gt- mre.ufsc.br/sobre.php>. Acesso em: 15 de abril de 2017.

MORAN, J. M. Educação inovadora presencial e a distância. 2003. Disponível em:<http://www.eca.usp.br/prof/moran/site/textos/tecnologias_eduacacao/inov.pdf> Acesso em: 27 mar. 2017.

NSES: National Research Council National science education standards, National Academy Press, Washington, DC. 1996. Disponível em:

$<$ http://www.nap.edu/catalog/9596/inquiry-and-the-national-science-educationstandards-a-guide-for>. Acesso em: 3 de Maio de 2016.

POON, C.-L.; TAN, D.; TAN, A.-L. Classroom Management and Inquiry-Based Learning: Finding the Balance. Science Scope, v. 32, n. 9, p. 18-21, 2009. SILVA, J. B. A utilização da experimentação remota como suporte para ambientes colaborativos de aprendizagem. 2006. 196 f. Tese (Doutorado) - Universidade Federal de Santa Catarina, Florianópolis, 2006.

VALENTE, J. A. A escola como geradora e gestora do conhecimento: o papel das tecnologias de informação e comunicação. Tecnologias emergentes: organizações e educação. São Paulo: Cengage Learning, 2008. 
VIEIRA, F. A. C. Ensino por investigação e aprendizagem significativa crítica: análise fenomenológica do potencial de uma proposta de ensino. 2012. $144 \mathrm{f}$. Tese (Doutorado em Educação para a Ciência) - Universidade Estadual Paulista, Bauru, 2012. 